Supporting Information

\title{
Solubilization of tetrahydroxyphenylchlorin in water and improved photodynamic activity after complexation with cyclic oligo- and polysaccharides
}

Keita Yamana, Riku Kawasaki, Kouta Sugikawa, and Atsushi Ikeda*

Department of Applied Chemistry, Graduate School of Engineering, Hiroshima University, 1-4-1 Kagamiyama, Higashi-Hiroshima, 739-8527, Japan

Corresponding Author: Atsushi Ikeda (aikeda@hiroshima-u.ac.jp) 


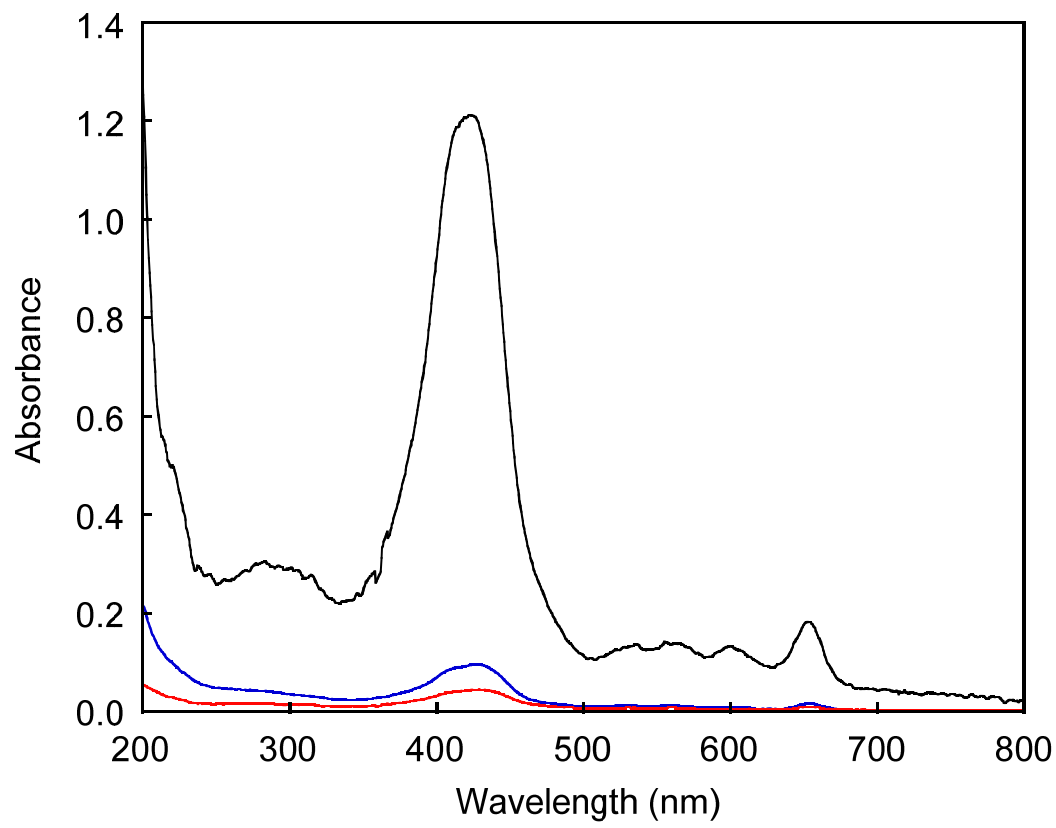

Figure S1. UV-vis absorption spectra of the pullulan-2 (red), arabinogalactan-2 (blue), and $\lambda$-carrageenan-2 (black) complexes in water after HSVM (1-mm cell). All of solutions were diluted to $1 / 3$. 

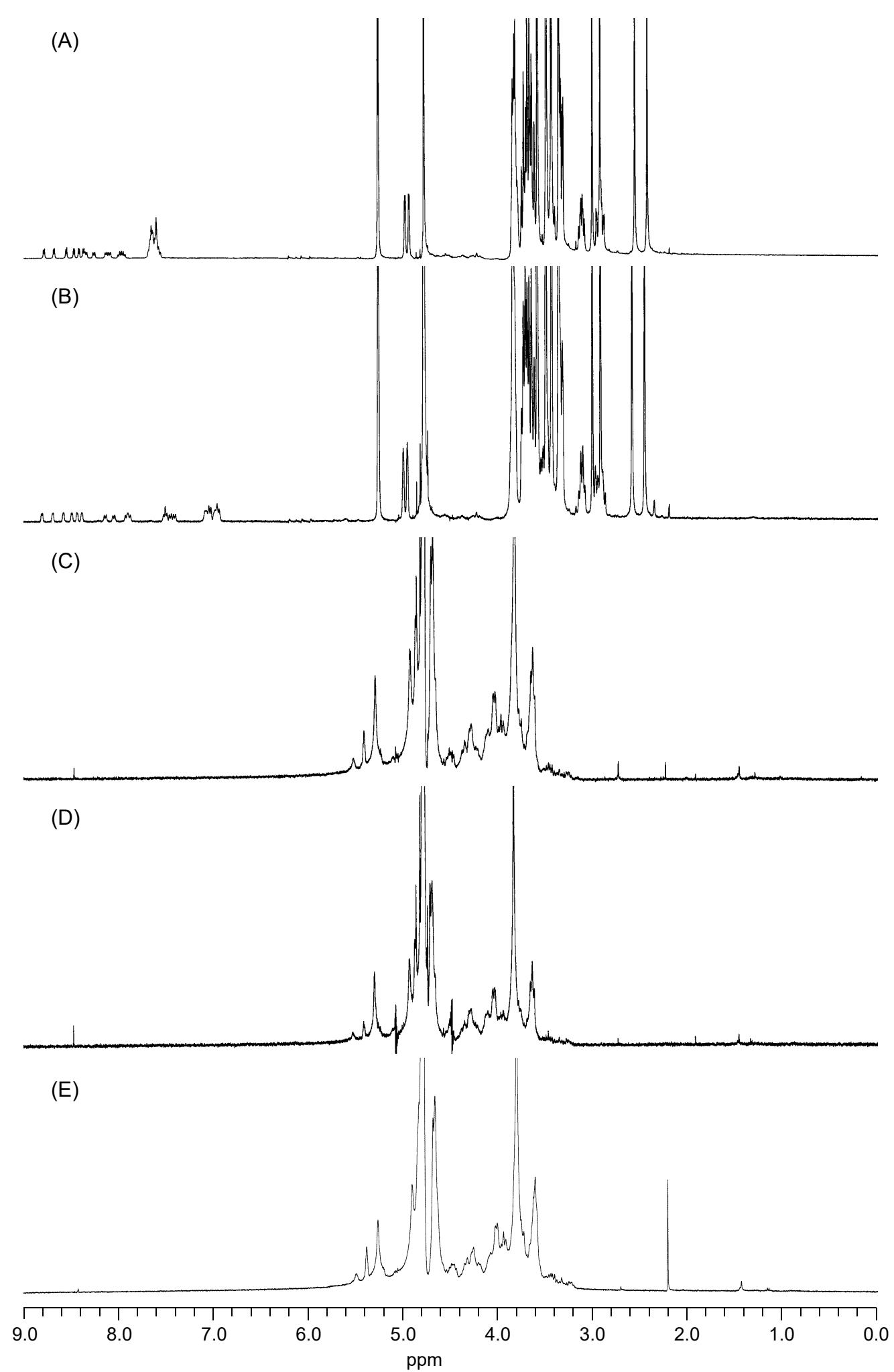

Figure S2. Complete ${ }^{1} \mathrm{H}$ NMR spectra of (A) TMe $\beta C D-1$, (B) TMe $\beta C D-2$, (C) $\lambda$-carrageenan-1, (D) $\lambda$ carrageenan-2 complexes, and (E) $\lambda$-carrageenan in $\mathrm{D}_{2} \mathrm{O}$. 


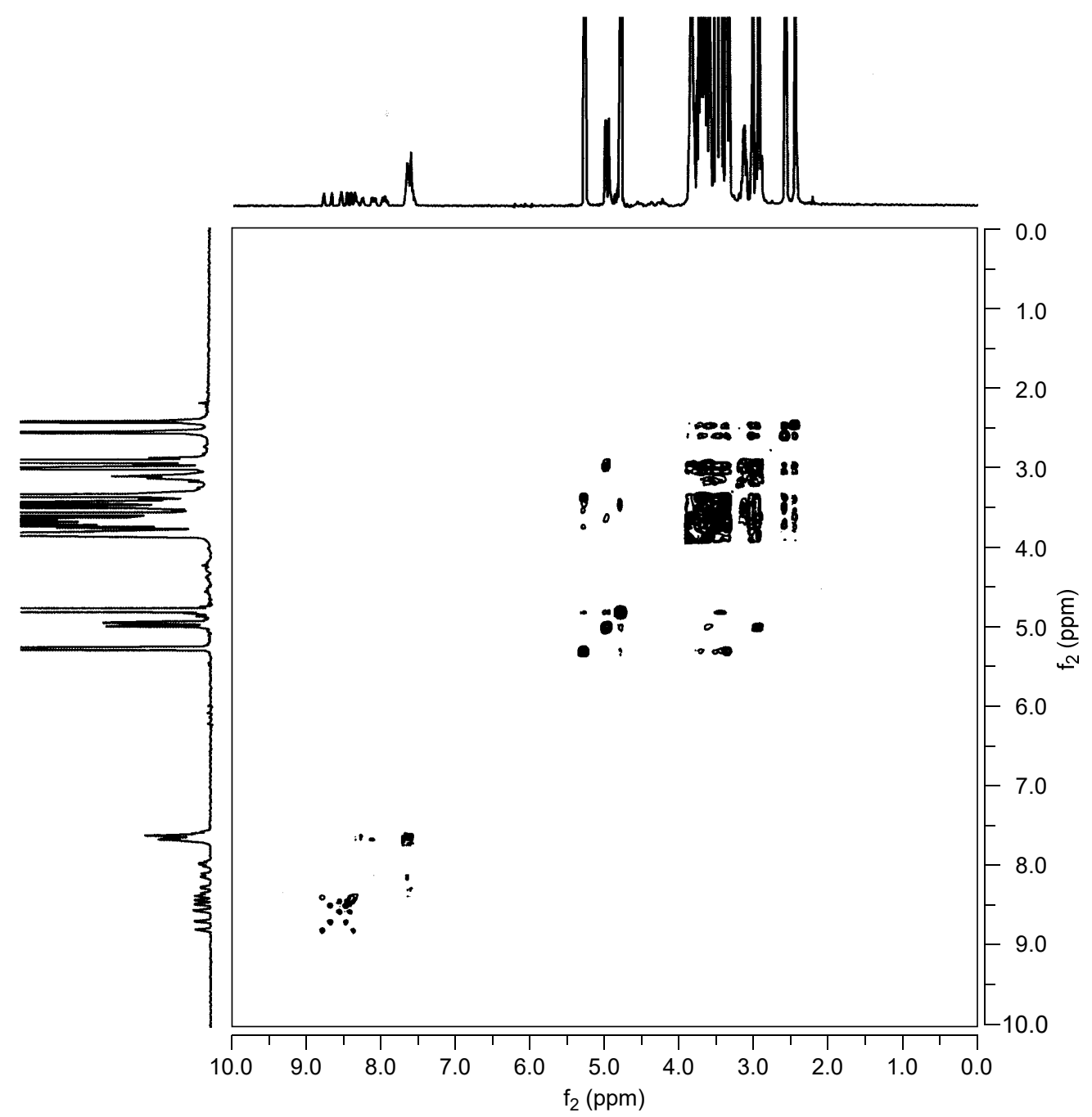

Figure S3. $2 \mathrm{D}{ }^{1} \mathrm{H}-{ }^{1} \mathrm{H}$ COSY spectrum of the TMe $\beta \mathrm{CD}-1$ complex in $\mathrm{D}_{2} \mathrm{O}$ at $25^{\circ} \mathrm{C}$. 

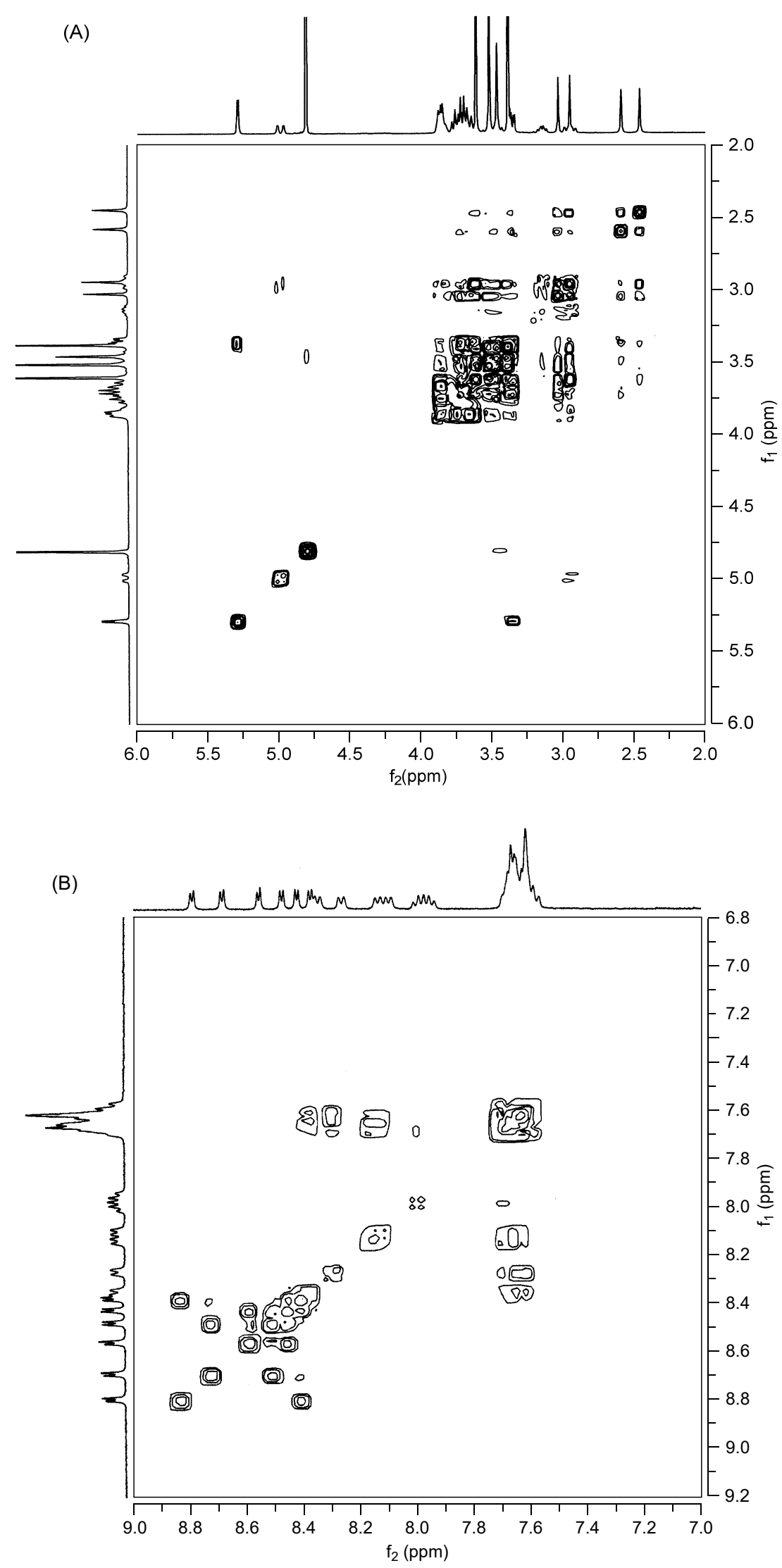

Figure S4. Partial $2 \mathrm{D}^{1} \mathrm{H}-{ }^{1} \mathrm{H}$ COSY spectra of the TMe $\beta \mathrm{CD}-1$ complex in the (A) 2.0-6.0 ppm and (B) 7.09.0 ppm regions in $\mathrm{D}_{2} \mathrm{O}$ at $25^{\circ} \mathrm{C}$. 


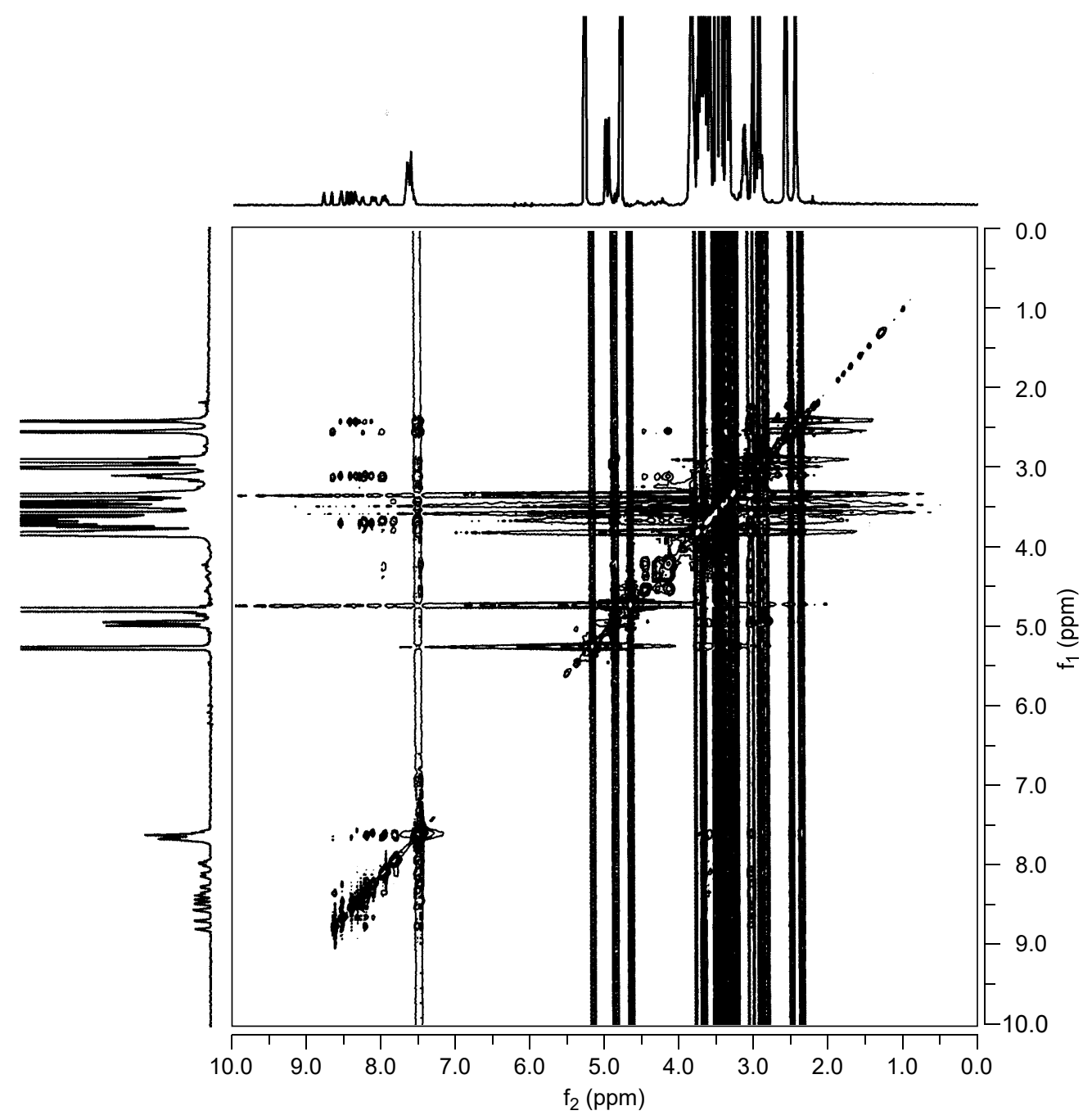

Figure S5. $2 \mathrm{D}{ }^{1} \mathrm{H}-{ }^{1} \mathrm{H}$ NOESY spectrum of the TMe $\beta \mathrm{CD}-1$ complex in $\mathrm{D}_{2} \mathrm{O}$ at $25^{\circ} \mathrm{C}$. 

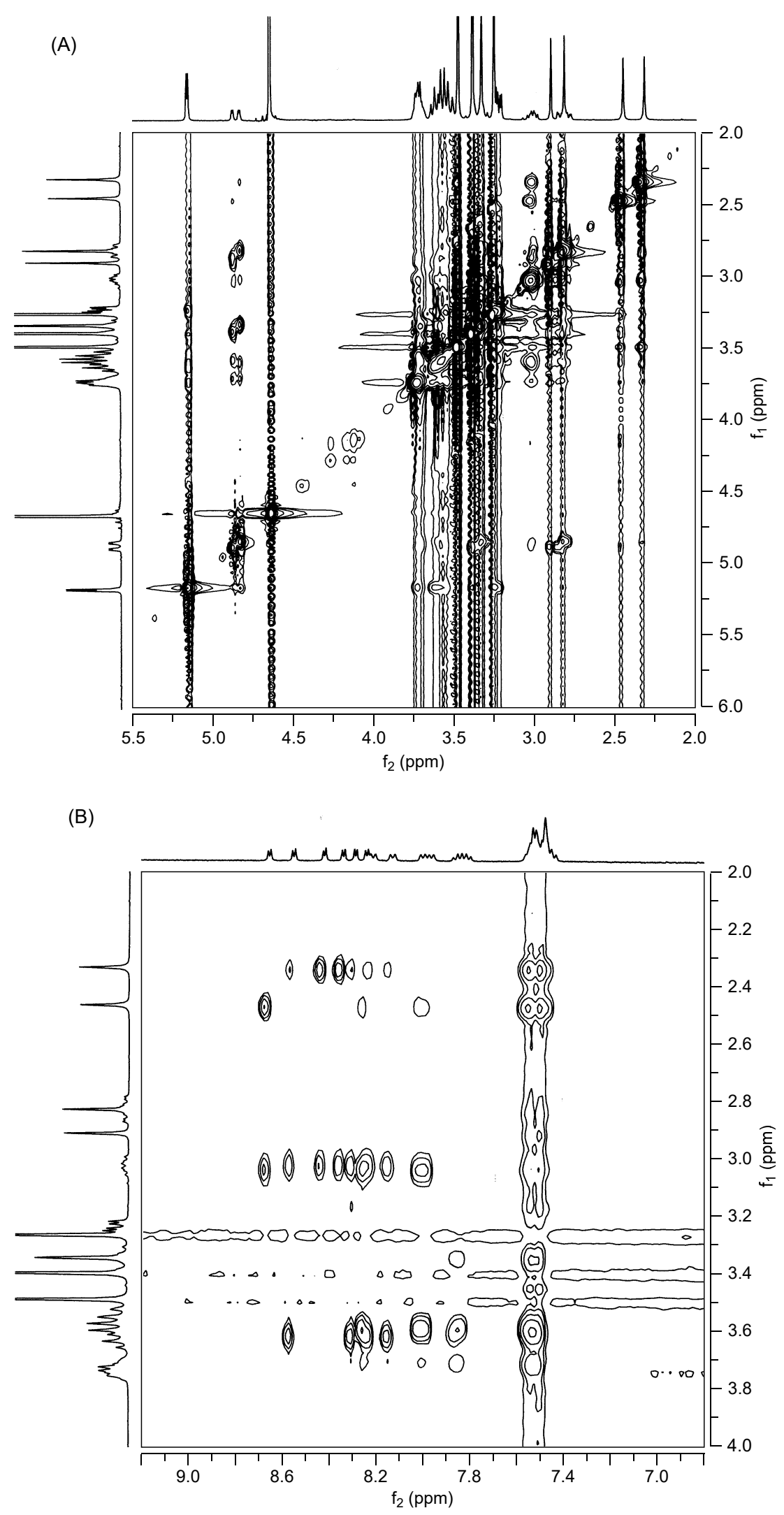

Figure S6. Partial 2D ${ }^{1} \mathrm{H}-{ }^{1} \mathrm{H}$ NOESY spectra of the TMe $\beta C D-1$ complex in the (A) $\mathrm{f}_{1}=2.0-6.0$ and $\mathrm{f}_{2}=2.0-$ 5.5 ppm regions and $(B) f_{1}=2.0-4.0$ and $\mathrm{f}_{2}=6.8-9.2$ ppm regions in $\mathrm{D}_{2} \mathrm{O}$ at $25^{\circ} \mathrm{C}$. 


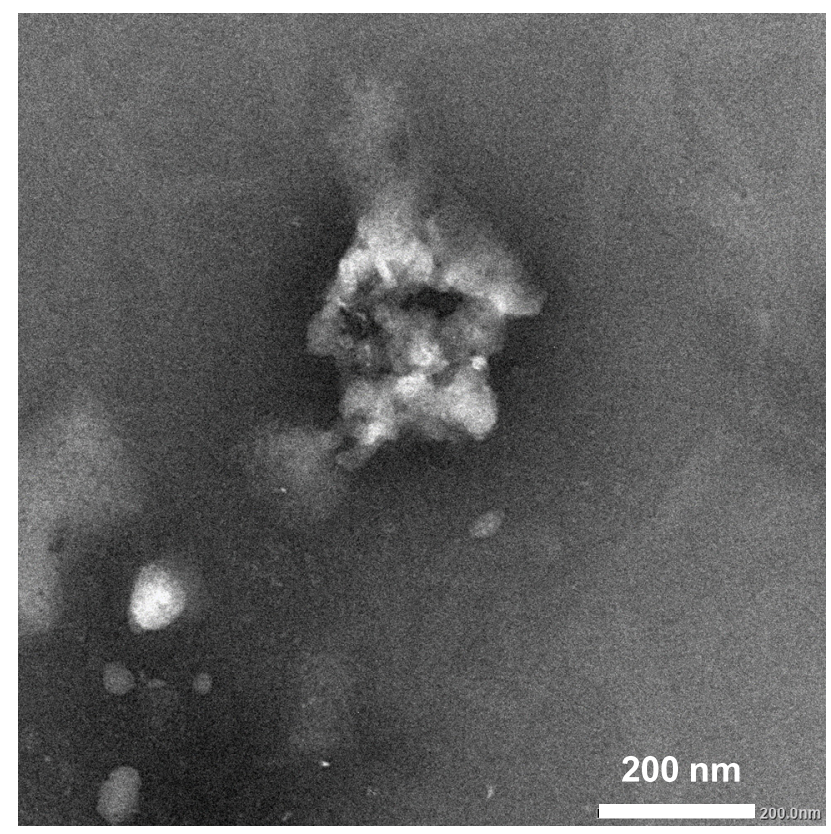

Figure S7. A TEM image of the $\lambda$-carrageenan-2 complex (negative staining, $1.5 \mathrm{wt} \%$ ammonium molybdate). 
(A)

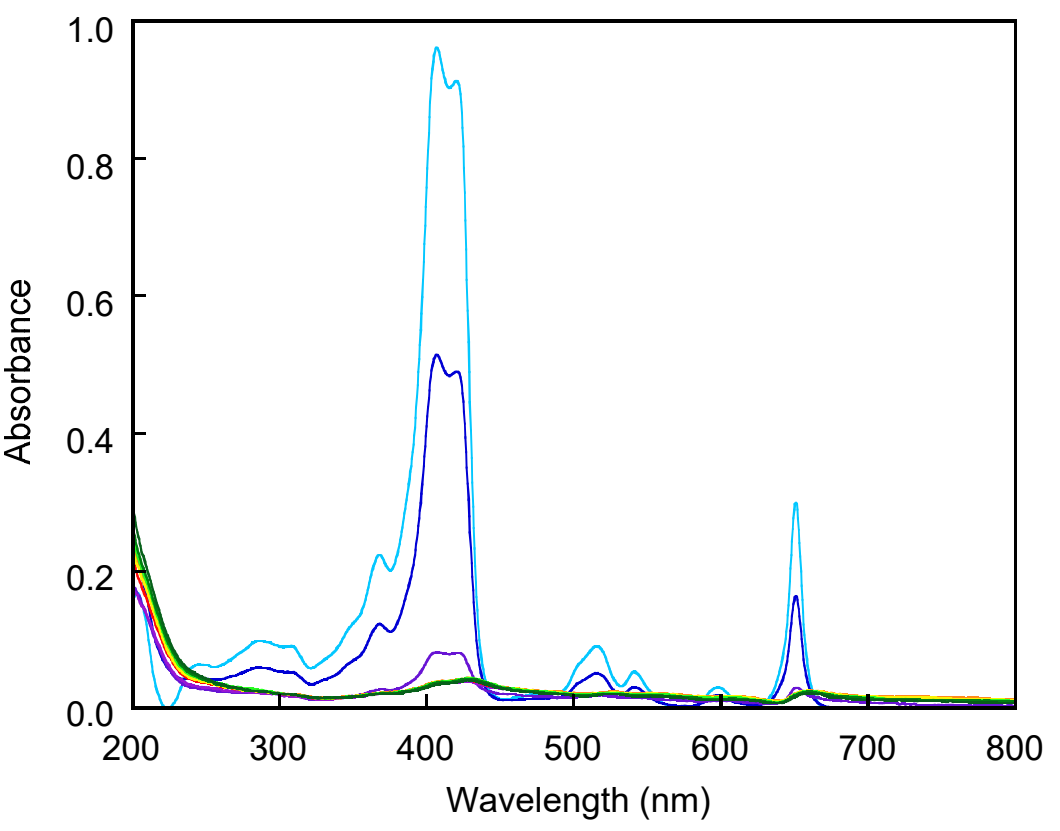

(B)

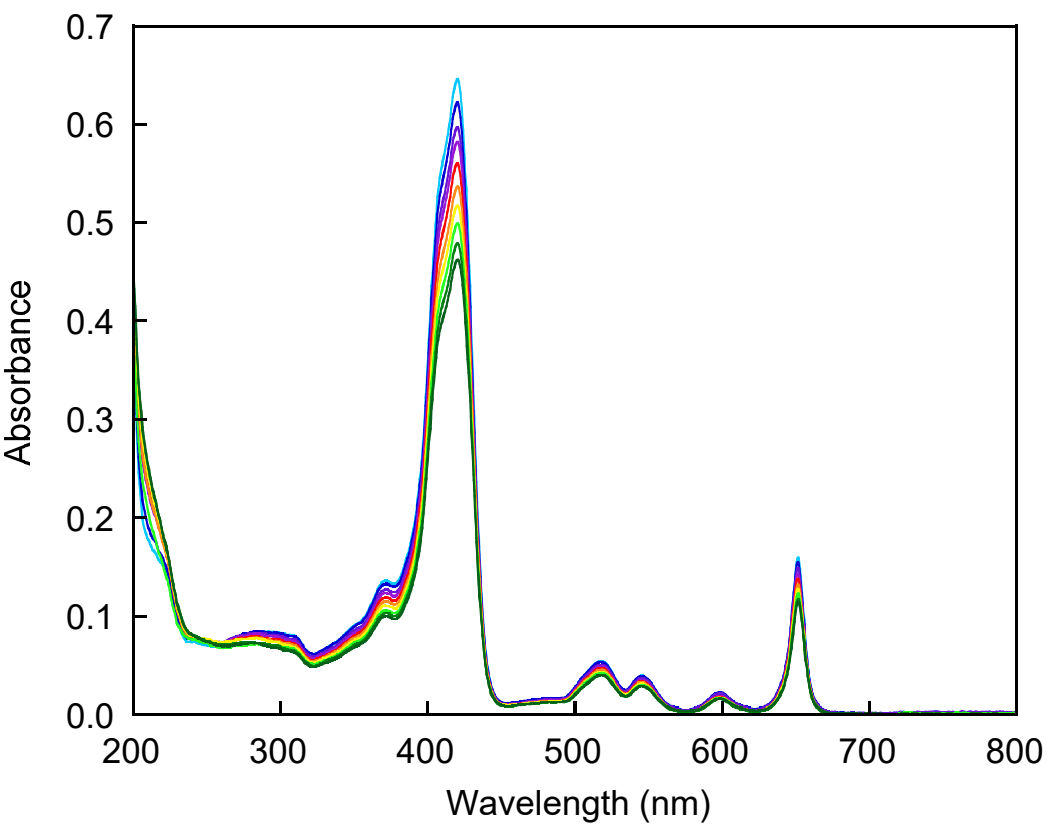

Figure S8. Changes in UV-vis absorption by the (A) TMe $\beta$ CD-1 and (B) TMe $\beta$ CD-2 complexes in aqueous solutions at $25^{\circ} \mathrm{C}$ following incubation for 0 (light blue), 0.25 (blue), 0.5 (deep purple), 1 (purple), 2 (red), 3 (orange), 4 (yellow), 5 (yellow-green), 6 (green), and 7 (dark green) days. Spectra were collected at $25{ }^{\circ} \mathrm{C}$ with 1 and 2 at concentrations of $5.0 \mu \mathrm{M}$ using a $1-\mathrm{cm}$ cell. 

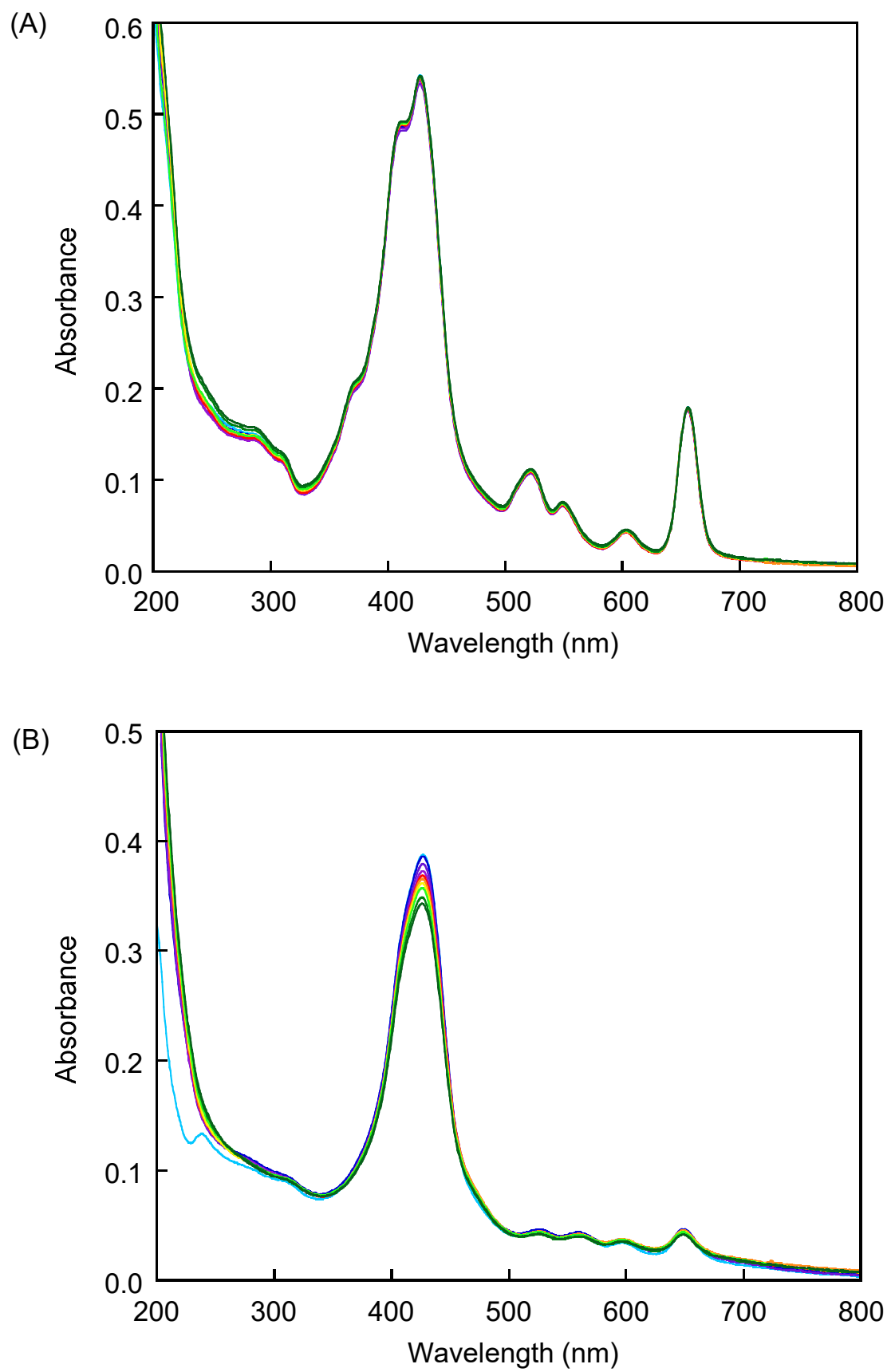

Figure S9. Changes in UV-vis absorption by the (A) $\lambda$-carrageenan-1 and (B) $\lambda$-carrageenan-2 complexes in aqueous solutions at $25{ }^{\circ} \mathrm{C}$ following incubation for 0 (light blue), 0.25 (blue), 0.5 (deep purple), 1 (purple), 2 (red), 3 (orange), 4 (yellow), 5 (yellow-green), 6 (green), and 7 (dark green) days. Spectra were collected at $25^{\circ} \mathrm{C}$ with 1 and 2 at concentrations of $5.0 \mu \mathrm{M}$ using a $1-\mathrm{cm}$ cell. 


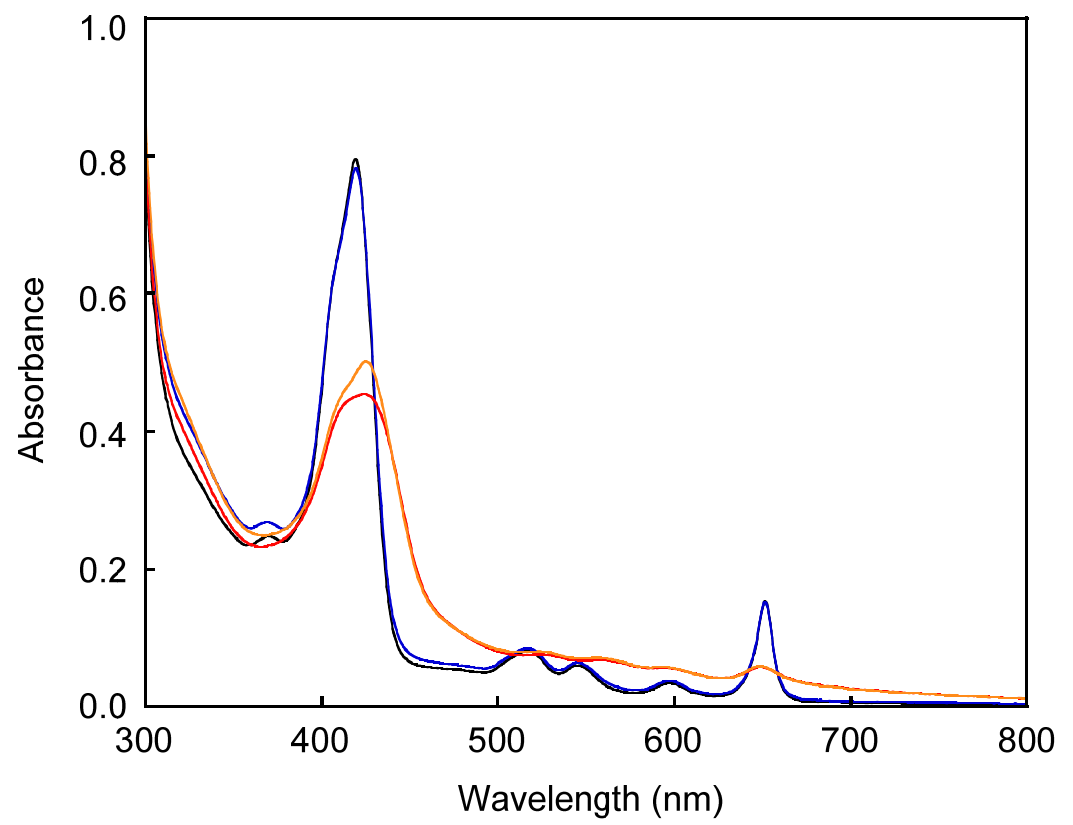

Figure S10. UV-vis absorption spectra of the TMe $\beta$ CD-2 complex (black and blue) and $\lambda$-carrageenan-2 complex (red and orange) with incubation times of 0 (black and red) and 24 (blue and orange) $\mathrm{h}$ in a buffer containing serum protein using fatal bovine serum (FBS) with maintaining temperature at $37{ }^{\circ} \mathrm{C}$. The absorption spectra were recorded at $25^{\circ} \mathrm{C}(1-\mathrm{cm}$ cell). The concentration of 2 was $5.0 \mu \mathrm{M}$. 
(A)

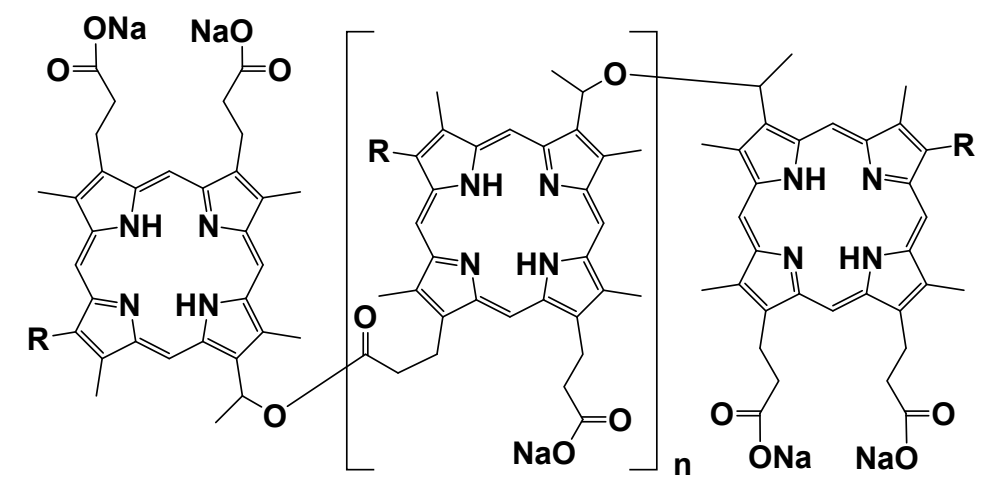

Photofrin $\quad \mathrm{R}=\underset{-\underset{\mathrm{C}}{\mathrm{O}} \mathrm{CH}}{\mathrm{C} \mathrm{CH}_{3}}$ or $-\mathrm{CH}=\mathrm{CH}_{2} \quad \mathrm{n}=0-6$

(B)

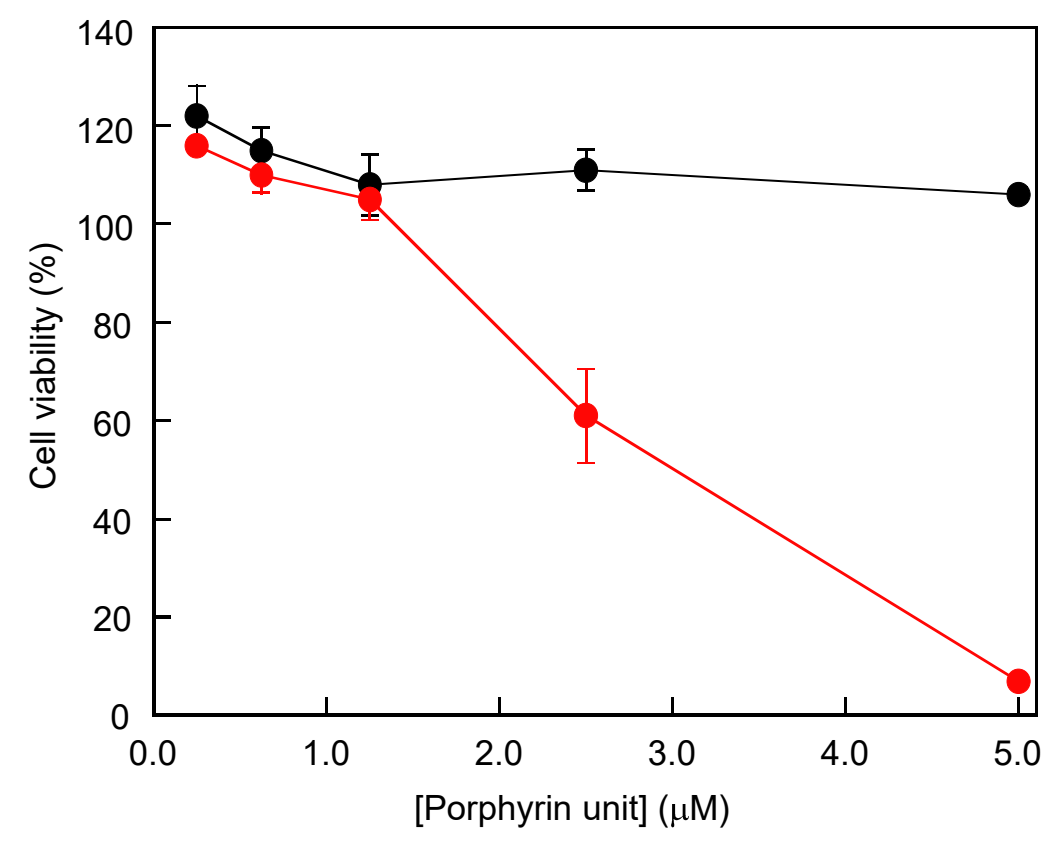

Figure S11. (A) Structure of Photofrin and (B) the cytotoxicity of Photofrin in the absence (black) and presence (red) of light irradiation at $610-740 \mathrm{~nm}$ for $30 \mathrm{~min}$. Cell viability was evaluated according to the WST-8 method. Each value represents the mean \pm standard deviation (SD) of three experiments $(n=3)$. 
(A)

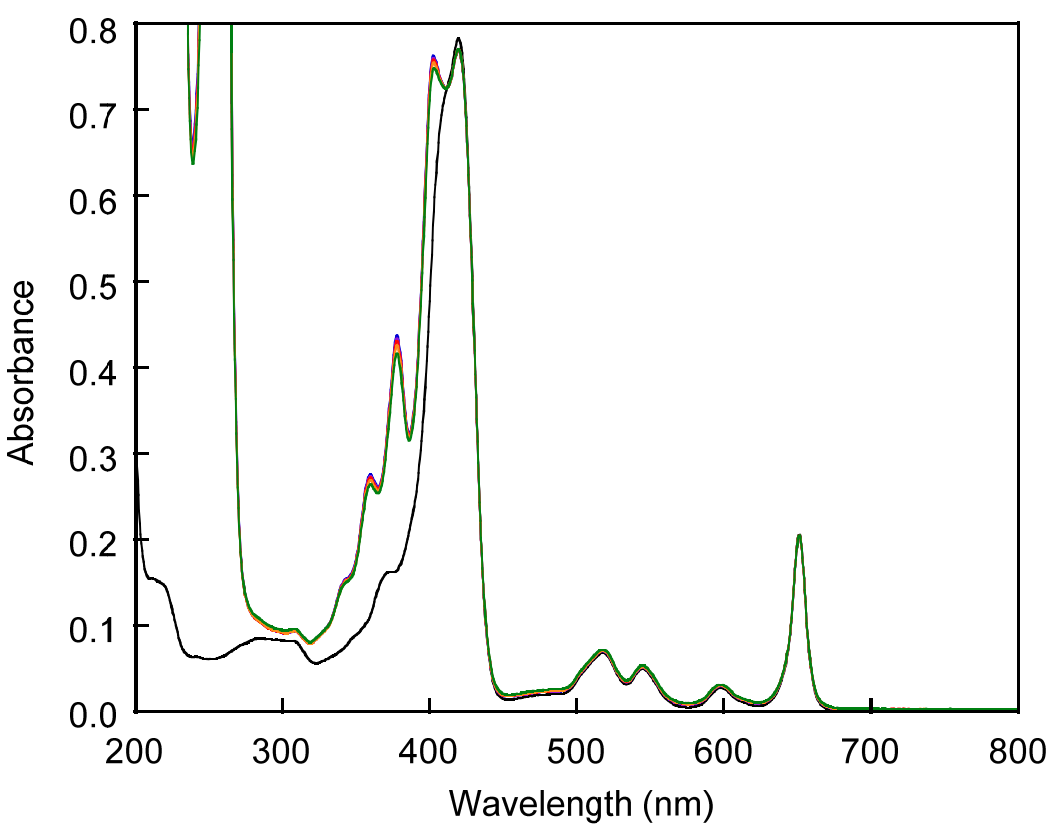

(B)

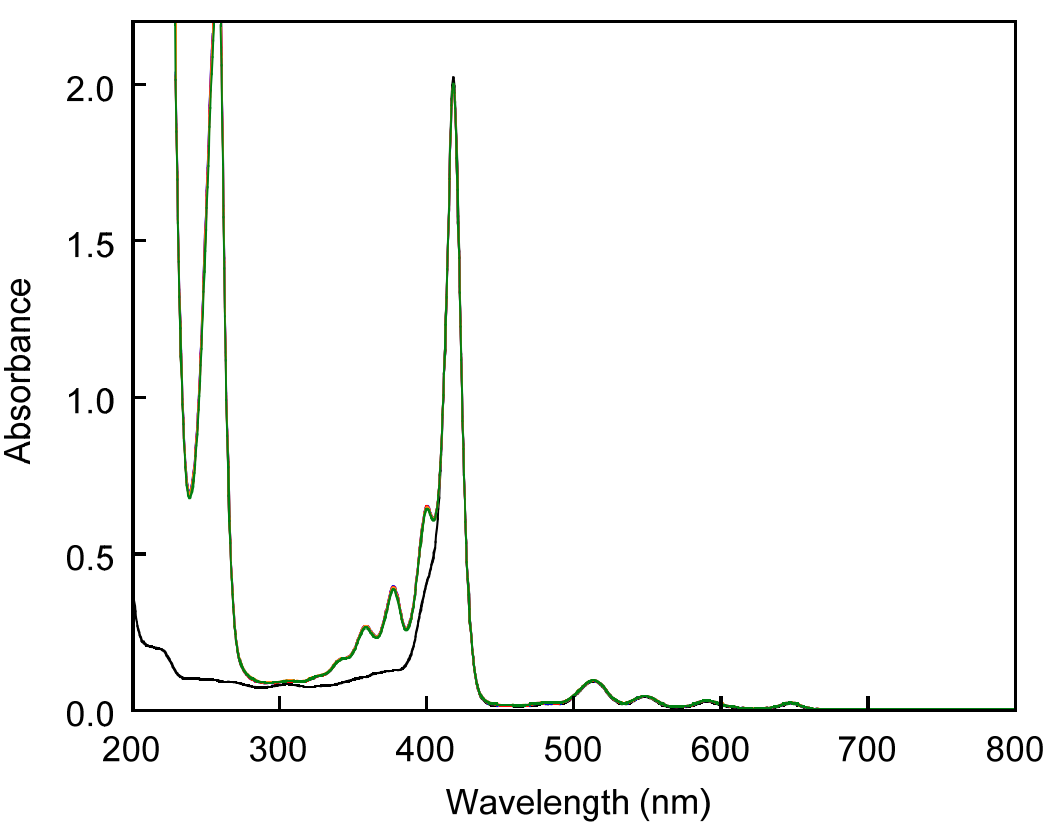

Figure S12. Changes in UV-vis absorption by ABDA in the presence of (A) the TMe $\beta C D-2$ complex and (B) the TMe $\beta$ CD-4 complex before (black) and after the addition of ABDA and photoirradiation at a wavelength of $>620 \mathrm{~nm}$ for 0 (blue), 7.5 (purple), 15 (red), 30 (orange), and 60 (green) min at an irradiation power of $15 \mathrm{~mW} \mathrm{~cm}{ }^{-2}$. The absorption spectra were recorded in an oxygenated atmosphere at $25{ }^{\circ} \mathrm{C}(1-\mathrm{cm}$ cell). The concentrations of 2 and 4 were $6.0 \mu \mathrm{M}$. [ABDA] $=25 \mu \mathrm{M}$. 
(A)

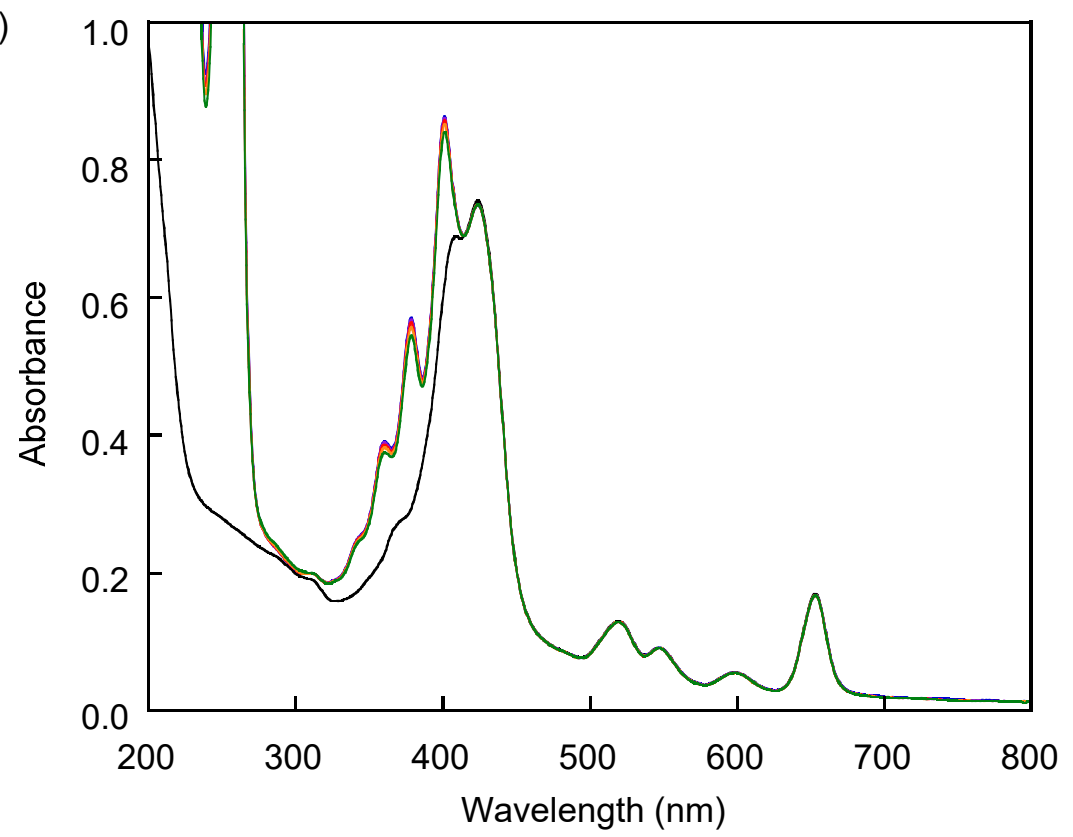

(B)

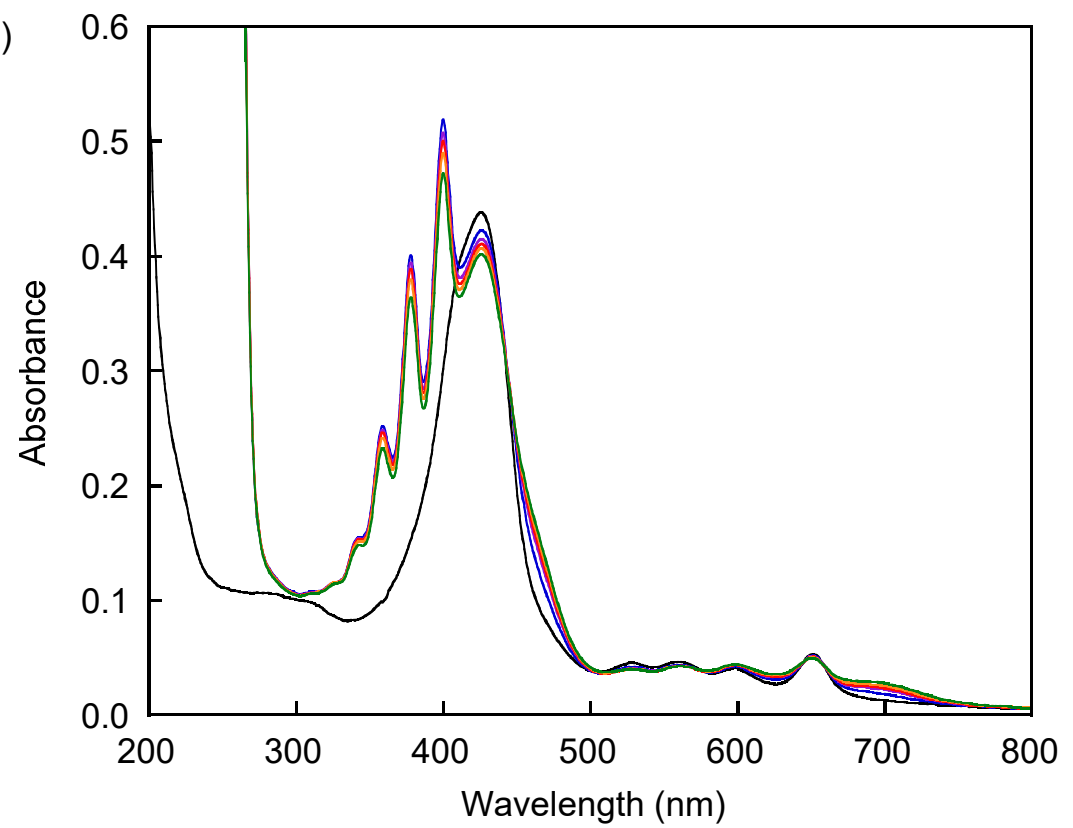

Figure S13. Changes in UV-vis absorption by ABDA in the presence of (A) the $\lambda$-carrageenan- $\mathbf{1}$ complex and (B) the $\lambda$-carrageenan-2 complex before (black) and after the addition of ABDA and photoirradiation at a wavelength $>620 \mathrm{~nm}$ for 0 (blue), 7.5 (purple), 15 (red), 30 (orange), and 60 (green) min in an oxygenated atmosphere at a photoirradiation power of $15 \mathrm{~mW} \mathrm{~cm}{ }^{-2}$. The absorption spectra were recorded at $25{ }^{\circ} \mathrm{C}(1-$ $\mathrm{cm}$ cell). The concentrations of 1 and 2 were $6.0 \mu \mathrm{M}$. [ABDA] $=25 \mu \mathrm{M}$. 


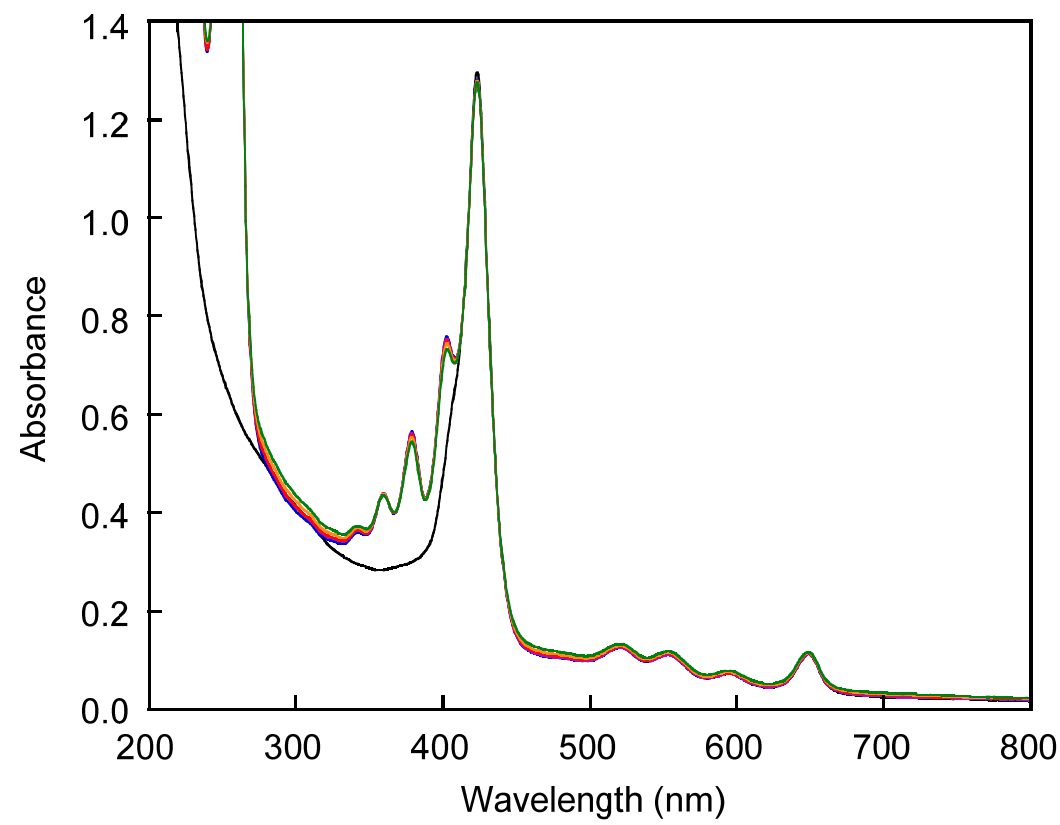

Figure S14. Changes in UV-vis absorption by ABDA in the presence of the $\lambda$-carrageenan-2 complex and DMPC-liposomes before (black) and after the addition of ABDA and photoirradiation at a wavelength $>620$ $\mathrm{nm}$ for 0 (blue), 7.5 (purple), 15 (red), 30 (orange), and 60 (green) min in an oxygenated atmosphere at a photoirradiation power of $15 \mathrm{~mW} \mathrm{~cm}{ }^{-2}$. The absorption spectra were recorded at $25^{\circ} \mathrm{C}(1-\mathrm{cm}$ cell). [2] $=6.0$ $\mu \mathrm{M},[\mathrm{DMPC}]=1.0 \mathrm{mM},[\mathrm{ABDA}]=25 \mu \mathrm{M}$. 
(A)

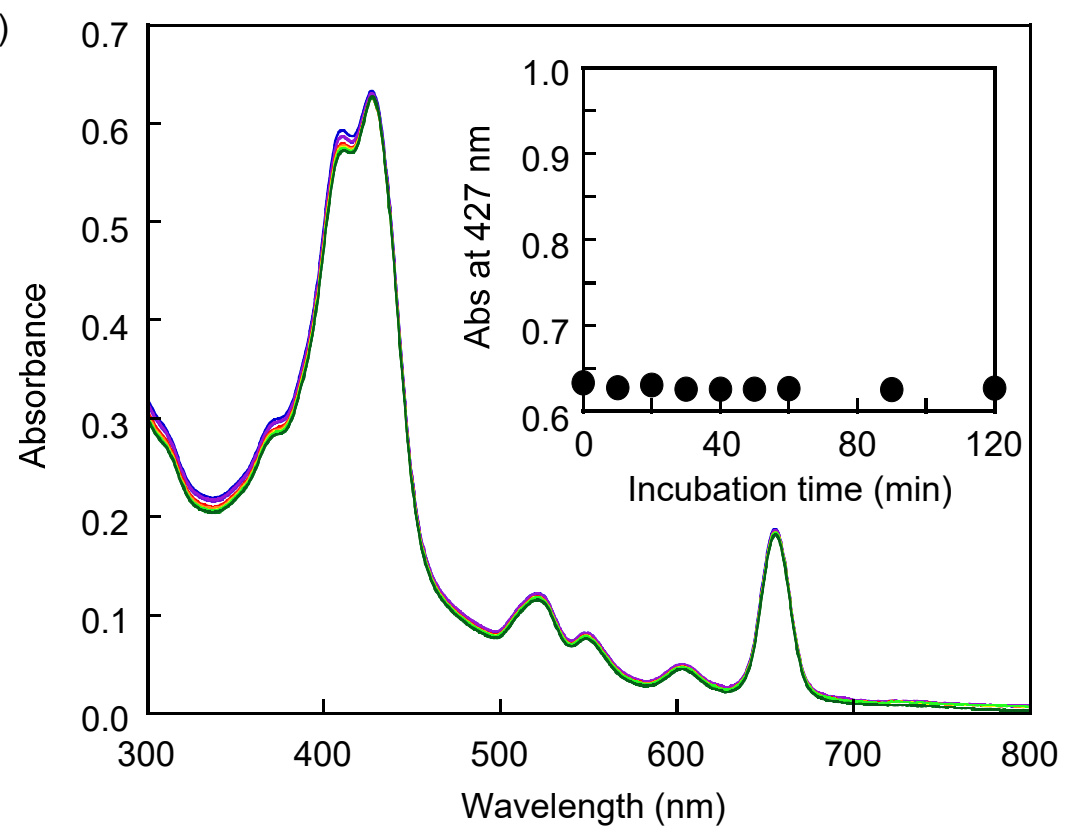

(B)

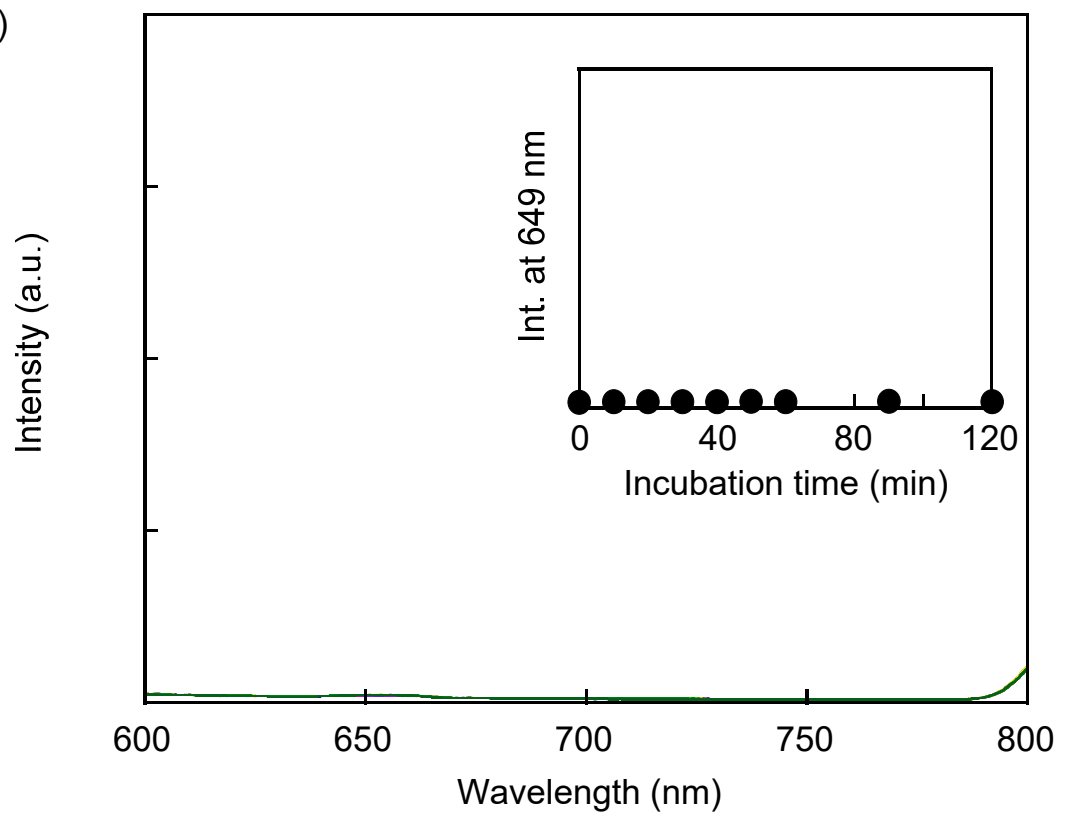

Figure S15. Time-dependent changes in $\lambda$-carrageenan-1 complex (A) UV-vis absorption and (B) fluorescence intensity at $\lambda_{\mathrm{ex}}=540 \mathrm{~nm}$ for 0 (blue), 10 (deep purple), 20 (purple), 30 (red), 40 (orange), 50 (yellow), 60 (yellow-green), 90 (green), and 120 (dark green) min after the addition of DMPC liposomes at $80{ }^{\circ} \mathrm{C}([1]=5.0 \mu \mathrm{M},[\mathrm{DMPC}]=1.0 \mathrm{mM})$. The inset in $(\mathrm{A})$ shows the dependence of absorbance at $426 \mathrm{~nm}$ on incubation time. The inset in (B) shows the dependence of fluorescence intensity at $649 \mathrm{~nm}$ on incubation time. 

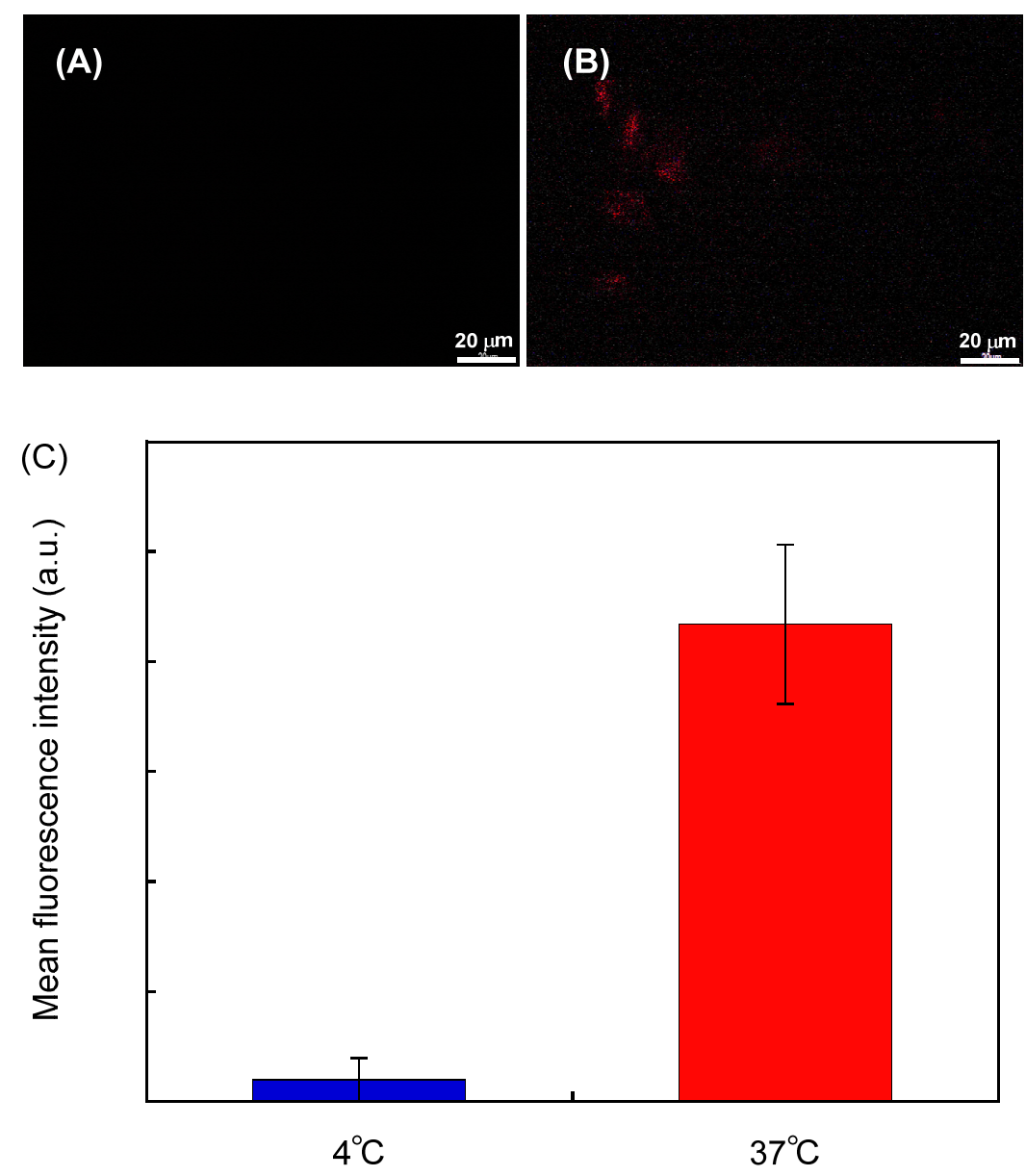

Figure S16. Endocytosis inhibition assay. HeLa cells were treated with the $\lambda$-carrageenan-2 complex at $4{ }^{\circ} \mathrm{C}$ (A) and $37^{\circ} \mathrm{C}$ (B) for $2 \mathrm{~h}$. After incubation, the samples were observed by fluorescence microscopy. (C) The fluorescence intensities in the images of more than 50 cells analyzed using ImageJ. 


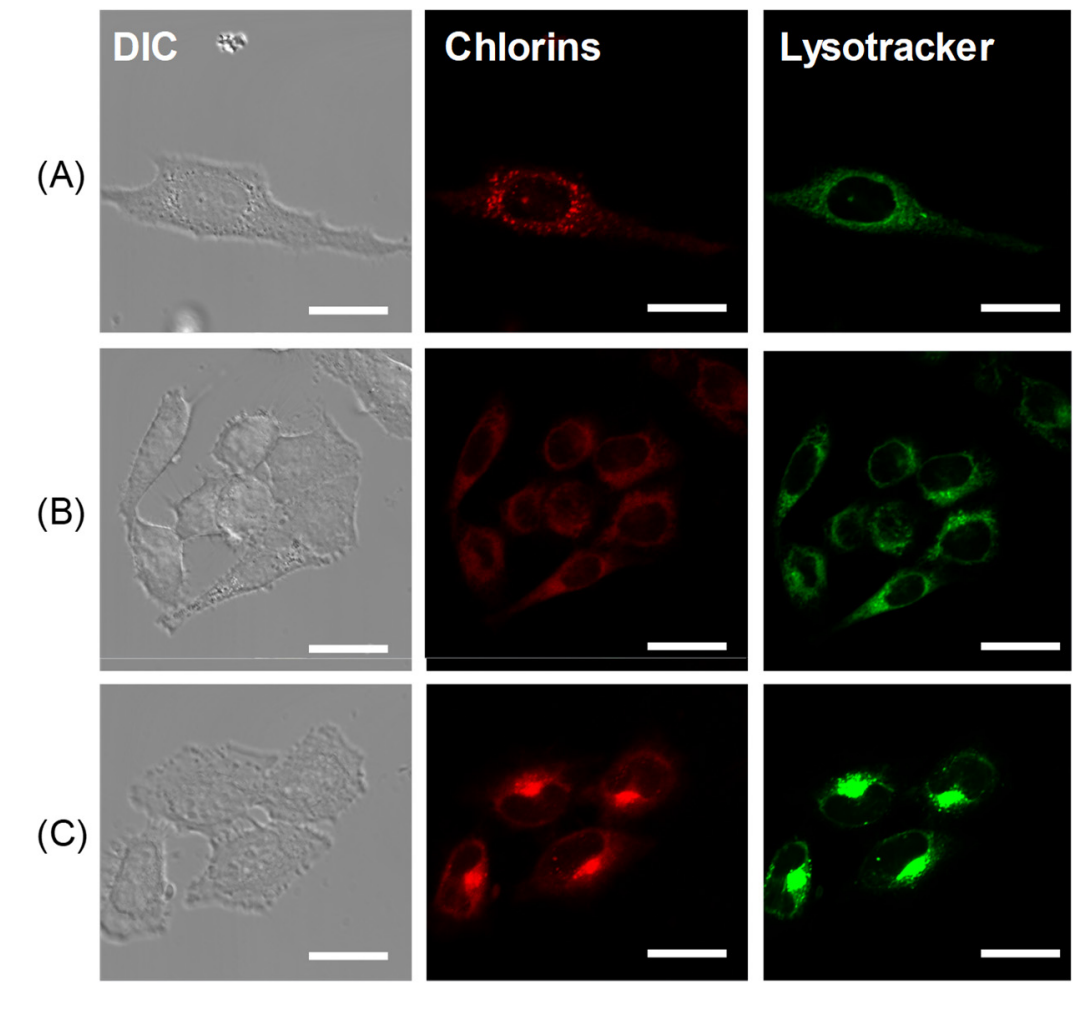

Figure S17. Co-localization of delivered chlorin derivatives with lysosomes. HeLa cells were co-incubated with the (A) TMe $\beta$ CD-1, (B) TMe $\beta$ CD-2, and (C) $\lambda$-carrageenan-2 complexes for $24 \mathrm{~h}$. The lysosomes were then stained with Lysotracker Green. The samples were observed by confocal laser scanning microscopy. Red, green, and yellow areas indicate the presence of delivered chlorin derivatives, Lysotracker Green, and overlapping pixels, respectively. The scale bar represents $20 \mu \mathrm{m}$. 